\title{
Rapid preliminary modeling of transport reactor cores ${ }^{*}$
}

\author{
Vladimir I. Korolev ${ }^{1}$ \\ 1 Admiral Makarov State university of Maritime and Inland shipping (SUMIS), 5/7 Dvinskaya Str., Saint-Petersburg, 198035, Russia \\ Corresponding author: Vladimir I. Korolev (vlikor2007@yandex.ru)
}

Academic editor: Yury Kazansky • Received 5 Deccember 2019 Accepted 17 Deccember 2020 Published 30 March 2021

Citation: Korolev VI (2021) Rapid preliminary modeling of transport reactor cores. Nuclear Energy and Technology 7(1): 41-47. https://doi.org/10.3897/nucet.7.65310

\begin{abstract}
At the present time, JSC Baltiskiy zavod has built and transported to the deployment site at Pevek Akademik Lomonosov, a floating nuclear power unit (FNPU), project 20870. There are also three multi-purpose nuclear icebreakers of project 22220 (Arktika, Sibir, Ural) under construction at Baltiskiy being at different readiness stages. A decision has been made to build a nuclear icebreaker, Lider, of even a higher power. Integral reactors developed by JSC OKBM Afrikantov are installed in the nuclear icebreakers using new assembly-type cores which have not been used earlier in floating facilities. A great deal of preliminary calculation is required to give these cores as advantageous characteristics as possible. The paper proposes a procedure for rapid modeling of floating cores with varied operating and design characteristics. This procedure can be used as part of preliminary modeling. The procedure is based on using a combined dimensionless parameter proposed by the author in (Korolev 2009). A chart is presented to model the key performance of cores for floating objects with a nuclear reactor NPPs. Eight assembly-type core options, which can be installed in transport reactors of a modular or integral design, are analyzed.
\end{abstract}

\section{Keywords}

Core, energy resource, combined dimensionless parameter, nuclear fuel, burn-up depth, fission products, fuel element, fuel matrix, uranium dioxide, swelling compensator, cladding integrity, effective life

\section{Introduction}

Reactor cores for nuclear powered floating facilities were developed in two major stages using different design approaches dictated by the demands of the time. Fig. 1 shows a diagram that explains the key requirements to the reactor cores of nuclear powered floating facilities and the relationships between them.

The objective at stage 1 was to build a high-power reactor core, primarily for the needs of the Soviet Navy. It took quite a long time to achieve the required core performance since no desired reliability could be ensured because of the core's high power rating of $\sim 165 \mathrm{MW} / \mathrm{m}^{3}$
(KLT-40). It should be noted that the heat density of fixed reactor cores was $\sim 80 \mathrm{MW} / \mathrm{m}^{3}$ (VVER-440) and $\sim 110 \mathrm{MW} / \mathrm{m}^{3}$ (VVER-1000). Long-term integrity of the fuel cladding was also an issue hard to resolve. Another problem caused by the high power rating of ship reactor cores was surface boiling of the coolant on the fuel cladding at power values of over $60 \%$ of the rated power. This phenomenon was attributed to the "nodular (spot) corrosion" of zirconium fuel cladding (Polunichev and Golubeva 2009) leading to its failure. A long period of improvements was required to achieve the acceptable core reliability. As the result, the requirements for bringing closer the core energy resource and energy content

* Russian text published: Izvestiya vuzov. Yadernaya Energetika (ISSN 0204-3327), 2020, n. 4, pp. 50-62. 

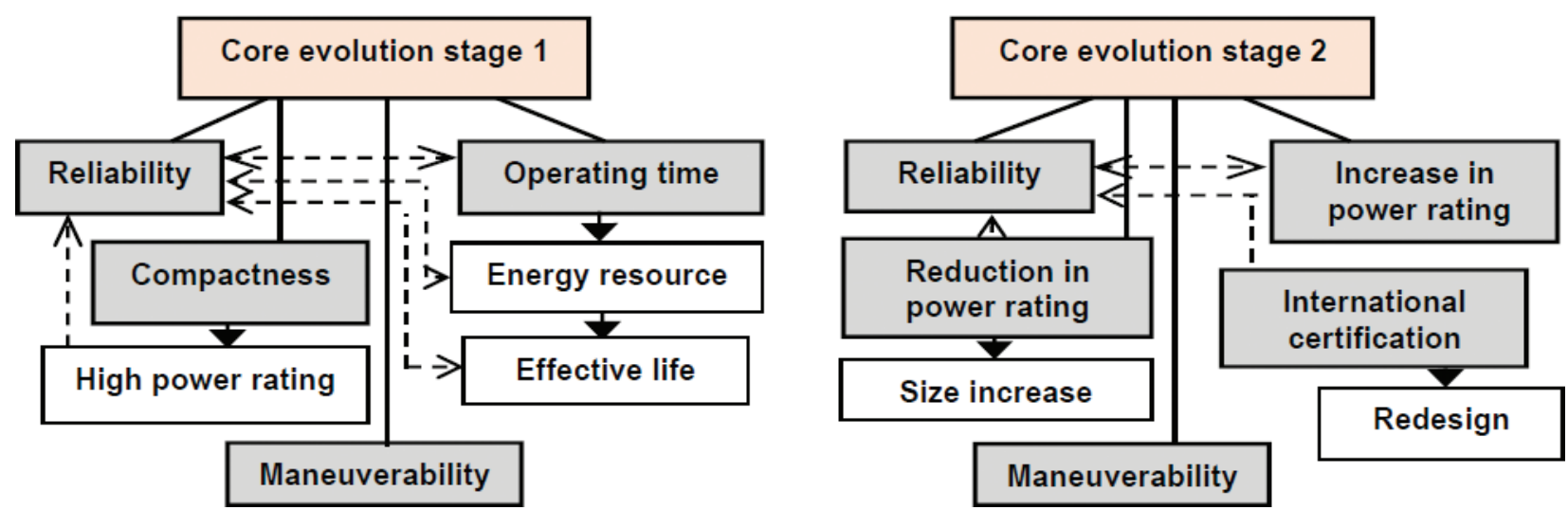

Figure 1. Diagram of the key requirements to the reactor cores of nuclear powered floating facilities and internal relationships between them for ships built in 1975-2007 (projects 1052, 10521, 10580) and for modern vessels (projects 20870 PEB, 22220 UAL).

have been satisfied by varying the core design characteristics and performance.

The conceptual approach was changed at stage 2 since cores were largely designed for civilian floating facilities, and it became possible to promote them at international market (the path towards globalizing Russian nuclear technologies proclaimed by Rosatom State Corporation). Further, the core developers and manufacturers were aimed at giving cores a better reliability and higher energy content. At the same time, it was not stringently required to make cores compact. More importantly, the challenges of the time set the goal to ensure that Russian transport reactor cores be recognized internationally. Later cores were therefore significantly improved. The monoblock (integral) reactor design (project 22220) made it possible to increase to a certain extent the core dimensions and to improve their energy content. Given the long-term perfection of the cores from evolution stage 1, one should expect the situation to be the same for the second stage core. The author proposes a procedure for the rapid preliminary modeling of reactor cores differing in design characteristics and performance.

\section{Methods and materials}

Improving the energy resource and energy content of transport reactor cores requires a study to be undertaken into the core design and performance parameters. The integrity of fuel cladding depends to a certain extent on the maximum in-core heat flux density $q_{s}^{\max }$ and the maximum specific accumulation of fission products in dispersion fuel $g_{\mathrm{fp}}{ }^{\max }$. The combination of the above parameters may have an independent value. For instance, the relation $\xi=q_{s}^{\max } / g_{\mathrm{fp}}{ }^{\max }\left[\mathrm{MW} \cdot \mathrm{cm}^{3} \times \mathrm{m}^{-2} \times \mathrm{g}^{-1}\right]$ characterizes the core heat density, on the one hand, and the energy content in terms of the loaded fuel amount and the energy resource in terms of the fuel cladding reliability, on the other hand. A higher value of this relation can be achieved at the expense of increasing the core power rating and reducing the fuel cladding reliability due to a greater probability of the core integrity loss or the core volume increase with the achieved burn-up depth. Formally then, for the emerging trends in the core design and construction in future the value $\xi$ will tend to decrease: for the cores of the nuclear icebreakers in operation (evolution stage 1), $\xi=1.9$ to 2.0; for the floating power unit (FPU) core (Akademik Lomonosov), $\xi=1.3$; and for the multipurpose nuclear icebreaker core (Arktika), $\xi=0.58$ (evolution stage 2) (Korolev and Lastovtsev 2017).

The second core evolution stage also involves a number of trends towards (Korolev and Lastovtsev 2017):

- reducing the core specific power rating, $\mathrm{MW} / \mathrm{m}^{3}$;

- reducing the core specific heat flux, $\mathrm{MW} / \mathrm{m}^{2}$;

- increasing the fuel heat-exchange surface area, $\mathrm{m}^{2}$;

- increasing the core volume, $\mathrm{m}^{3}$;

- increasing the core effective life, h;

- increasing the specific fission product accumulation, $\mathrm{g} / \mathrm{cm}^{3}$.

A dimensionless combined parameter was proposed in (Korolev 2009, Korolev and Lastovtsev 2008, 2010a) which includes essential core design and performance characteristics and defines directly the core reliability (energy resource) and the fuel element design. This parameter can be used for analyzing preliminarily new engineering solutions when modeling reactor cores for floating objects with a nuclear reactor NPPs:

$$
K r=4<k>\xi T_{\mathrm{ef}} / d_{\mathrm{fe}},
$$

where $\langle k\rangle$ is the average specific consumption of fissionable nuclides for the core life, $\mathrm{g} /(\mathrm{MW} \times$ day $)$.

For thermal neutron reactors, the probability of the $\mathrm{U}-235$ thermal neutron capture without fission is $\sim 0.15$, that is, each five or six fissioned U-235 nuclei give birth to the nucleus of the non-fissionable U-236 isotope the formation of which means that the fissionable nucleus is lost without energy generation. The probability of the Pu239 transformation to a non-fissionable $\mathrm{Pu}-240$ isotope is 0.26 . Therefore, the presence of radiation capture reactions, which compete with the fission reaction, inevitably leads to an inefficient increase in the specific consumption 
of fissionable nuclides. As follows from the above, $\langle k\rangle=$ $1.20-1.22 \mathrm{~g} /(\mathrm{MW} \times$ day $)$ in thermal neutron reactors $(\mathrm{Ku}-$ znetsov 1988).

For illustration, Fig. 2 presents a semi-graphical model of the nuclear fuel burn-up as a function of the core energy generation and operating conditions. In the process of fuel burn-up, the mass of the fissionable parent U-235 isotope decreases ( $A C$ curve) as the mass of the bred fissionable $\mathrm{Pu}-239$ isotope increments ( $0 N$ curve). The quantity of the fissionable plutonium isotopes formed depends on the total core energy generation and the secondary fuel integral breeding factor.

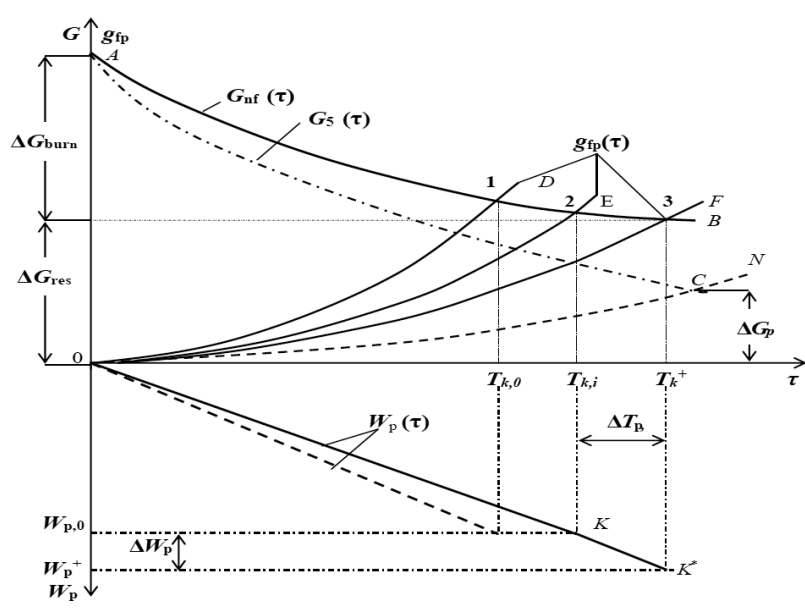

Figure 2. A semi-graphical model of nuclear fuel burn-up as a function of the core energy generation and operating conditions: $A C$ curve - variation of the parent $\mathrm{U}-235$ isotope mass; $0 N$ curve - increment of the bred Pu-239 isotope mass; $\Delta G_{\mathrm{e}}$ - equilibrium mass of initial fuel and bred fuel; point 1 - in-core accumulation of fission fragments during reactor rated power operation and with the core's normal thermophysical parameters; point 3 - accumulation of fission fragments during the reactor core operation at a power less than the rated power and with variation of the core's thermophysical parameters $-0 F$ curve

With a high nuclear fuel burn-up, the concentrations of uranium-235 and plutonium-239 account nearly equally for the energy generation in the reactor (Kuznetsov 1988). The equilibrium mass of the initial fuel and the fuel bred, $\Delta G_{\mathrm{p}}$, is determined in the intersection of the $A C$ and $0 N$ curves.

The highest accumulation rate of fission fragments takes place during the reactor rated power operation $(0 D$ curve) with the energy content exhausting the fastest (effective life, $T_{\text {eff }}$ ).

The reactor is kept in a critical condition up to point 1 where the qualitative variation curve of the fissionable nuclide total mass $(A B)$ intersects with the qualitative curve of the in-core fission fragment accumulation during the reactor rated power operation and with the core's normal thermophysical parameters $(0 D)$. The energy generation will be $W_{\mathrm{p}, 0}$ (estimated core energy content).

If, for example, the average coolant temperature is reduced, the total energy generation can be increased to the value $W_{\mathrm{p}}^{+}$. The reactor is kept critical up to point 3 (see
Fig. 2) where the curve $A B$ intersects with the curve of the fission fragment accumulation during the reactor core operation at a power smaller than the rated power and with variation of the core's thermophysical parameters $(0 F)$. The evolution of the processes shown in the figure qualitatively coincides with the computer-based calculations of neutronic performance for the nuclear fuel burn-up in ship reactors. The development of the semi-graphical model did not aim to show numerical values.

For transport reactor cores, the average specific consumption of U-235 for the core life is determined as $\langle k\rangle^{*}$ $=G_{5}{ }^{0} / W_{\mathrm{p}, 0}, \mathrm{~g} /(\mathrm{MW} \times$ day $)\left(\langle k\rangle^{*}=1.86-2.1\right)$ where $G_{5}{ }^{0}$ is the initial core U-235 weight load.

The dimensionless combined parameter for transport reactor cores can be also found from the relation

$$
\left.K r=\left[1-2<\delta_{\mathrm{cl}}\right\rangle\right]^{2}\left(1-k_{\mathrm{sc}}{ }^{2}\right),
$$

where $k_{\mathrm{sc}}=\left\langle d_{\mathrm{sc}}\right\rangle /\left(1-2\left\langle\delta_{\mathrm{cl}}\right\rangle\right)$ is the correction factor taking into account the presence of the swelling compensator (SC) in the dispersion fuel composition; $\delta_{\mathrm{cl}}$ is the fuel cladding thickness; $\left\langle\delta_{\mathrm{cl}}\right\rangle=\delta_{\mathrm{cl}} / d_{\mathrm{fe}}$ is the relative fuel element cladding thickness; $\left\langle d_{\mathrm{sc}}\right\rangle=d_{\mathrm{sc}} / d_{\mathrm{fe}}$ is the relative equivalent diameter of the swelling compensator; and $d_{\mathrm{fe}}$ is the fuel element diameter.

The value of the parameter $K r$ depends only on the peculiarities of the fuel rod design used in the given core. The value $K r$ is directly proportional to the fuel element diameter and is inversely proportional to the fuel cladding thickness and the volume occupied by the swelling compensator (SC), that is, actually, the larger is the fuel composition cross-section area in the fuel's overall cross-section, the higher is the value of the parameter $\mathrm{Kr}$.

Using the dimensionless parameter $K r$ in practical design allows solving different core design optimization problems at the preliminary stage (preliminary design). The parameter $K r$ can be looked upon as a criterion of similarity for a certain set of cores in which fuel rods are used. An increased value of the parameter $K r$, all other things being equal, suggests an increased relative volume of the fuel composition and more uranium loaded into the fuel element (in a broad meaning of uranium intensity). In heterogeneous cores, in essence, $\mathrm{Kr}<1$ in each case. In homogeneous cores, $K r=1$ since they have no cladding and other structural fuel components. To improve the reliability of fuel in a heterogeneous core, normally, one needs to reduce the value $K r$, that is, the amount of the uranium loaded into fuel elements (SC installation in the fuel element, introduction of the gap between the cladding and the fuel, etc.). In this respect, the dimensionless parameter $K r$ can be taken as the fuel homogenization parameter. If a fuel element has much of its cross-section area occupied by structural components, the value of the parameter $K r$ will be smaller.

For a circular fuel element with the cladding diameter $d_{\mathrm{cl}}{ }^{\mathrm{fe}}=5.8 \mathrm{~mm}$ and the cladding thickness $\delta_{\mathrm{cl}}=0.5 \mathrm{~mm}$, the parameter $K r=0.685$. Where a cross-shaped fuel element is used with the same fuel cross-section area, $d_{\mathrm{cl}}{ }^{\mathrm{fe}}$ 
$=7 \mathrm{~mm}, \delta_{\mathrm{cl}}=0.5 \mathrm{~mm}$, then $K r=0.735$. Adding an SC to the fuel element has reduced its uranium intensity and the value $K r$. With $d_{\mathrm{cl}}{ }_{\mathrm{fe}}=5.8 \mathrm{~mm}$ and $\delta_{\mathrm{cl}}=0.5 \mathrm{~mm}$, and the swelling compensator diameter being $d_{\mathrm{sc}}=3.7 \mathrm{~mm}$, the value $K r$ decreases to 0.4 . For fuel elements with a gap between the cladding and the ceramic fuel elements, with $d_{\mathrm{cl}}^{\text {fe }}=9.1 \mathrm{~mm}, \delta_{\mathrm{cl}}=0.65 \mathrm{~mm}$, the gap width being $\delta_{\text {gap }}=0.125 \mathrm{~mm}$, and the internal hole diameter being $d_{\text {hole }}=1.4 \mathrm{~mm}$, the value $K r=0.67$.

On the whole, in transport reactor cores, the value of the parameter $K r$ will grow with the cladding diameter increase, the growth being the greater, the smaller is the diameter of the swelling compensator ( 0.35 to 0.85 ), and in fixed cores, respectively, with the hole diameter reduction in fuel elements ( 0.57 to 0.8 ) (Korolev and Lastovtsev 2017).

The higher is the parameter $K r$ with the given fuel cladding diameter, the more technologically perfect is the fuel element, provided its reliability is as required. Since it is not possible to eliminate fuel cladding in heterogeneous cores, increasing $\mathrm{Kr}$ requires the cladding thickness to be reduced, the gap between the cladding and the fuel to be decreased, and the SC and the internal hole to be eliminated. This requires then other engineering solutions to ensure reliable operation of fuel elements for producing the specified energy resource. One of the possible approaches is to use fuel with a self-compensating volume and ductile cladding.

An analysis of advanced fuel cladding materials has been undertaken at the National Nuclear Laboratory in Great Britain. Five major types of fuel cladding materials were considered with a different level of availability for being commercialized: improved zirconium alloys; ferrite and martensite steels; nickel-, vanadium- and chromium-based heat-resistant alloys; niobium-, tantalum-, molybdenum- and tungsten-based high-melting alloys; ceramic-based materials including fiber composites based on silicon carbide; MAX-ceramics, and zirconium carbide (Korolev and Lastovtsev 2017).

Expressions (1) and (2) can be used to determine the required diameter of the fuel cladding in meters (Korolev and Lastovtsev 2017). After the conversion we get

$$
d_{c l}^{f e}=0,5\left[A+4 \delta_{c l}+\sqrt{A\left(A+8 \delta_{c l}\right)}\right],
$$

where $\mathrm{A}=4\langle k\rangle \xi \mathrm{T}_{\mathrm{eff}} /\left(1-\mathrm{k}_{\mathrm{sc}}{ }^{2}\right)$ is the integrated indicator, $\mathrm{m}$.

Rapid modeling of transport reactor cores requires a connection to be established between the core design characteristics (circumscribed diameter and height), nuclear fuel load, number of fuel elements, etc. with the performance indicators, including maximum heat flux density, maximum specific accumulation of fission products (characteristics relation), effective life, and specific nature of the fuel design. The above performance indicators form a part of the integrated indicator $A$ that can be used as an argument in the preliminary evaluation of the core design characteristics.

In accordance with (Korolev and Lastovtsev 2017), the core diameter in meters can be found from the relation

$$
D_{\text {core }}=k_{d}^{*} \sqrt[3]{Q_{\mathrm{p}, 0} k_{\mathrm{v}}^{q} d_{f e} / q_{s}^{\max }},
$$

where $Q_{\mathrm{p}, 0}$ is the reactor facility rated power, MW; $k_{d}{ }^{*}=\left[k_{s} k_{\sigma}(1+\omega) /(\pi m)\right]^{1 / 3}=\left[k_{\text {cell }} k_{\sigma} /(\pi m)\right]^{1 / 3}$ is the coefficient allowing for the core design peculiarities: $k_{s}$ is the factor for taking into account the cell area increase due to the existence of the fuel cladding, FA shrouds, the burnable absorber, the CPS system absorber rods, and working and starting neutron source (WNS and SNS) rods $\left(k_{s}=1.3-\right.$ $1.5) ; k_{\sigma}=1-4\left\langle\delta_{\mathrm{cl}}\right\rangle+4\left\langle\delta_{\mathrm{cl}}\right\rangle^{2}-\left\langle d_{\mathrm{sc}}\right\rangle^{2}$ is the share of the cross-section occupied by the fuel composition $\left(k_{\sigma}=0.5\right.$ $-0.6) ; k_{v}^{q}$ is the bulk power peaking factor; and $\omega$ is the ratio of the moderator cross-section area to the fuel composition area across the elementary cell (variable in the limits of two to four for heterogeneous reactors).

If we assume that $\delta_{\mathrm{cl}}=0.5 \times 10^{-3} \mathrm{~m}$, then, with regard for (3), expression (4) can be transformed as

$$
D_{\text {core }}=7.94 \cdot 10^{-2} k_{d}^{*} \sqrt[3]{F_{f e}^{\Sigma}[2+A+\sqrt{A(A+4)}]},
$$

where $F_{\mathrm{fe}}^{\Sigma}=Q_{\mathrm{p}, 0} k_{\mathrm{v}}^{q} / q_{s}^{\max }$ is the total area fuel heat-exchange surface.

The initial core U-235 weight load, with regard for expression (3), where $\delta_{\mathrm{cl}}=0.5 \times 10^{-3} \mathrm{~m}$, can be presented as

$$
G_{5}^{0}=0.125 \cdot 10^{-3} \gamma_{5}{ }^{f m} F^{\Sigma}{ }_{f e} k_{\sigma}[2+A+\sqrt{A(A+4)}],
$$

where $\gamma_{5}{ }^{\mathrm{fm}}=\left(M_{5} / M_{\mathrm{fr}}\right) z_{5} \gamma_{\mathrm{fr}} b_{\mathrm{fr}}$ is the specific mass of U-235 in the fuel matrix volume unit, $\mathrm{kg} / \mathrm{m}^{3} ; M_{5}, M_{\mathrm{fr}}$ are the molecular weight of respectively U-235 and the fuel rods; $b_{\mathrm{fr}}$ is the volume fraction of the fuel rods in the dispersion fuel composition; $z_{5}$ is the fuel uranium-235 enrichment; and $\gamma_{\mathrm{fr}}$ is the specific weight of the fuel rods (uranium dioxide or intermetallic uranium).

The cores of ship reactors from evolution stage 1 (Korolev and Lastovtsev 2017) use fuel elements of intermetallic uranium, $\mathrm{U}\left(\mathrm{Al}_{4} \mathrm{Si}\right)_{3}$, dispersed into the Silumin matrix. The molecular mass of intermetallic uranium is

$$
\begin{aligned}
& M_{\text {imu }}=z_{5} \times M^{5}{ }_{\text {imu }}+\left(1-z_{5}\right) \times M^{8}{ }_{\text {imu }}= \\
& z_{5} \times 643+\left(1-z_{5}\right) \times 646 .
\end{aligned}
$$

It has been proposed that new cores should use uranium dioxide for fuel elements. Its molecular mass can be determined from the expression

$$
M_{\text {ud }}=z_{5} \times M_{\text {ud }}^{5}+\left(1-z_{5}\right) \times M_{\text {ud }}^{8}=z_{5} \times 267+\left(1-z_{5}\right) \times 270 \text {. }
$$

In accordance with the IAEA nuclear weapon nonproliferation requirement, the U-235 enrichment of the nuclear fuel used in reactor cores is limited to $z_{5}=0.2$. This requirement is applied to the cores from evolution stage 2 (Korolev and Lastovtsev 2017). Then the molecular mass of intermetallic uranium and uranium dioxide, as shown by expressions (7) and (8), will be respectively 645.4 and 269.4. Therefore, using ceramic fuel compositions $\left(\mathrm{UO}_{2}\right)$ makes it possible to increase the U-235 load, all other things being equal, by a factor of 2.4 as compared with intermetallic fuel. 
One cylindrical rod-type fuel element may contain a certain mass of fuel which is estimated using the expression

$$
\mathrm{M}_{f e}^{n f}=0.785 \cdot 10^{-6} \gamma_{5}^{f m} k_{\sigma} H_{\text {core }}\left\{0,5\left[A+4 \delta_{c l}+\sqrt{A\left(A+8 \delta_{c l}\right)}\right]\right\}^{2} .
$$

With regard for expressions (6) and (9), the number of fuel elements needed to be loaded into the core is estimated using the following formula

$$
n^{\Sigma}{ }_{f e}=0,637 \cdot 10^{3} F_{f e}^{\Sigma} /\left\{H_{\text {core }}[A+2+\sqrt{A(A+4)}]\right\},
$$

where $H_{\text {core }}$ is the core height.

The number of fuel elements in the core depends on the core diameter, the number of nodes in the core, the number and specific arrangement of the elements its comprises (fuel rods, FAs, burnable absorber rods, CPS absorber rods, WNS and SNS rods), and the ratio between the moderator cross-section area and the fuel composition area across the elementary cell. The number of FAs can be estimated using the formula

$$
n_{\mathrm{FA}}=D_{\text {core }}^{2} /\left(k_{\text {cell }} k_{\sigma}\left\langle k_{\mathrm{fe}}^{\mathrm{fill}}>d_{\mathrm{fe}}^{2} n_{\mathrm{nod}}^{\mathrm{FA}}\right),\right.
$$

where $n_{\text {nod }}$ FA is the number of nodes in the FA (chosen from the discrete series $61,91,127,169, \ldots)$; and $\left\langle k^{\text {fill }}{ }_{\mathrm{fe}}\right\rangle$ is the average coefficient of the FA filling with fuel elements (for stage 1 cores, $k_{\mathrm{fe}}^{\text {fill }}=0.84-0.87$, and for stage 2 cores, $\left.k_{\mathrm{fe}}^{\mathrm{fill}}=0.81-0.83\right)$

\section{Results}

Fig. 3 shows a chart to model the key characteristics of the reactors cores for nuclear powered floating facilities. The chart was built using formulas (5), (6), and (10). Fixed values were also taken for a number of quantities used in such formulas as $H_{\text {core }}, m, z_{5}, k_{\text {cell }}, k_{d}^{*}, k_{\sigma}, b_{\mathrm{fe}}$, and $\left\langle k_{\mathrm{fr}}^{\text {fill }}\right\rangle$. The core modeling using the diagram requires allowances to be introduced for the variation of the above quantity values. With regard for the corrections, formulas (5), (6), and (10) are reduced to the form

$$
\begin{gathered}
D_{\text {core }}=D_{\text {core }}{ }^{(\mathrm{d})} k_{n}^{d^{*}}, \\
G_{5}^{0}=k_{n}^{\mathrm{im}} k_{n}^{z} k_{n}^{b} k_{n}^{k \sigma} G_{5}^{0(\mathrm{~d})}, \\
n_{\mathrm{fe}}^{\Sigma}=n_{\mathrm{fe}}^{\Sigma(\mathrm{d})} / k_{n}^{H} .
\end{gathered}
$$

One can additionally estimate the required fuel enrichment $z_{5}$, the fuel matrix volume $V_{\text {fm }}$, the number of the FAs loaded into the core, $n_{\mathrm{FA}}$, and the calculated core energy content $W_{\mathrm{p}, 0}$ :

$$
\begin{gathered}
z_{5}=0.3436 \times 10^{-3} G_{5}^{0} /\left(k_{n}^{H} k_{n}^{b} k_{n}^{k \sigma} k_{n}^{\mathrm{im}} d_{\mathrm{fe}}{ }^{2} n_{\mathrm{fe}}^{\Sigma}\right), \\
V_{\mathrm{fm}}=0.518 k_{n}^{H} k_{n}^{k \sigma} d_{\mathrm{fe}}{ }^{2} n_{\mathrm{fe}}^{\Sigma}, \mathrm{m}^{3}, \\
n_{\mathrm{FA}}=D_{\text {core }}^{2} /\left(2.78 k_{n}^{\text {cell }} k_{n}^{k \sigma}\left\langle k_{n}^{\mathrm{fill}}>d_{\mathrm{fe}}{ }^{2} n_{\text {nod }}^{\mathrm{FA}}\right),\right.
\end{gathered}
$$
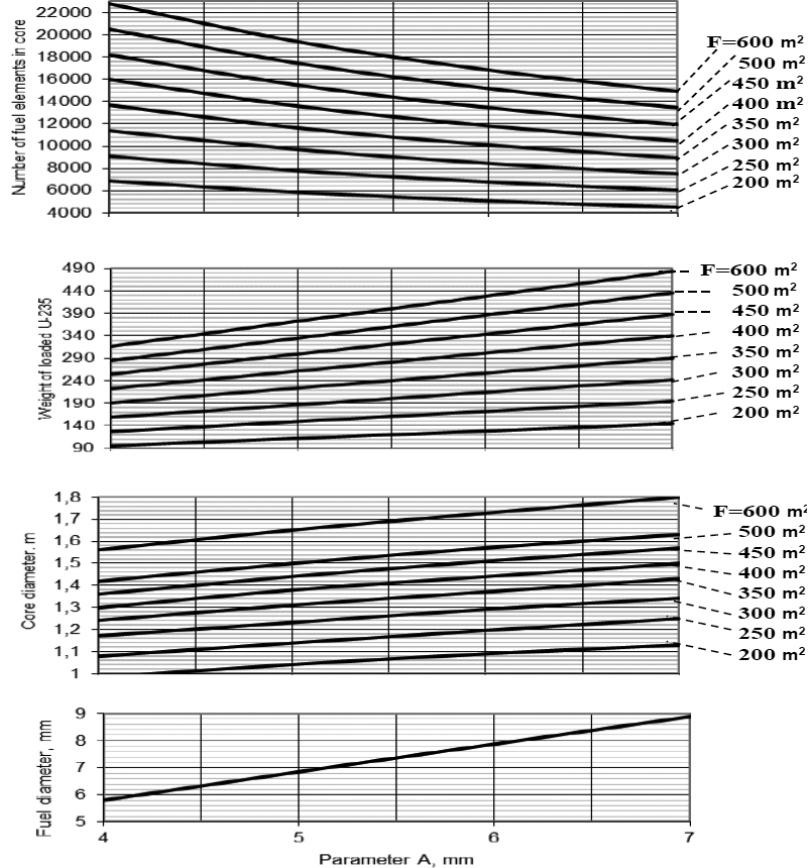

Figure 3. Nomogram for the preliminary modeling of the key design and performance characteristics of the nuclear powered floating facility reactor cores

$$
W_{\mathrm{p}, 0}=Q_{\mathrm{p}, 0} \times A\left(1-{k_{\mathrm{sc}}}^{2}\right) \times 10^{3} /(0.203 \xi), \mathrm{MW} \times \eta,
$$

where $D_{\text {core }}{ }^{(\mathrm{d})}, G_{5}{ }^{\text {(d) }}, n_{\text {fuel }}^{\Sigma}{ }^{(\mathrm{d})}$ are respectively the circumscribed core diameter, $\mathrm{m}$; the initial U-235 load, kg; the number of fuel elements in the core; $k_{n}^{d^{*}}=\left(k_{n}^{\text {cell }} k_{n}^{k \sigma} / k_{n}^{m}\right)$ is the allowance for the core diameter; $k_{n}^{\mathrm{im}}=0.418$ is the allowance for intermetallic uranium; $k_{n}^{z}=z_{5} / 0.141$ is the allowance for the fuel U-235 enrichment; $k_{n}^{b}=b_{\mathrm{fr}} / 0.59$ is the allowance for the volumetric content of fuel elements in the fuel composition; $k_{n}^{k \sigma}=\left\{1-4<\delta_{\mathrm{cl}}\right\rangle+4\left\langle\delta_{\mathrm{cl}}\right\rangle^{2}-\left[k_{\mathrm{sc}}(1\right.$ $\left.\left.-2\left\langle\delta_{\mathrm{cl}}\right\rangle\right]^{2}\right\} / 0.55$ is the allowance for the share of the fuel element cross-section occupied by the fuel composition; $k_{n}^{\text {cell }}=k_{s}(1+\omega) / 6.16$ is the allowance for the elementary cell cross-section; $\left\langle k_{n}{ }^{\text {fill }}\right\rangle=\left\langle k_{\mathrm{fe}}{ }^{\text {fill }}\right\rangle / 0.82$ is the allowance for the average coefficient of the FA filling with fuel elements; and $k_{n}^{H}=H_{\text {core }} / 1.2$ is the allowance for the core height.

Eight assembly-type core design options, which can be installed in transport reactors with modular or integral designs, are considered as an example. Estimates are based on a chart for modeling the key characteristics of the nuclear powered floating facility reactor cores. The variables included integrated indicator $A$, fuel element diameter $d_{\text {fe }}$, core rated thermal power $Q_{\mathrm{p}, 0}$, maximum heat flux density $q_{s}^{\max }$, characteristic ratio $\xi$, estimated core energy content $W_{\mathrm{p}, 0}$, total in-core fuel element heat-exchange surface $F_{\text {fe }}^{\Sigma}$, circumscribed core diameter $D_{\text {core }}$, fuel U-235 enrichment $z_{5}$, initial U-235 load $G_{5}^{0}$, and number of fuel elements in the core $n^{\Sigma}$ core.

The fuel element design characteristics were assumed to be in the following limits: relative cladding thickness $\left\langle\delta_{\mathrm{cl}}\right\rangle=0.056-0.073$; relative equivalent diameter of the swelling compensator $\left\langle d_{\mathrm{sc}}\right\rangle=0.34-0.418$; share of the fuel element cross-section occupied by the fuel composition, $k_{\sigma}=0.55-0.61$; volume fraction of the fuel ele- 
Table 1. Estimation results for transport reactor cores.

\begin{tabular}{|c|c|c|c|c|c|c|c|c|}
\hline \multirow[t]{2}{*}{ Description } & \multicolumn{8}{|c|}{ Option } \\
\hline & 1 & 2 & 3 & 4 & 5 & 6 & 7 & 8 \\
\hline Integrated indicator $\mathrm{A}, \mathrm{mm}$ & 4.9 & 4.9 & 6 & 7 & 6 & 4.9 & 4.9 & 4.9 \\
\hline Core rated thermal power $\mathrm{Q}_{\mathrm{p}, 0}, \mathrm{MW}$ & 150 & 175 & 175 & 175 & 315 & 315 & 315 & 175 \\
\hline Maximum heat flux density $\mathrm{q}_{\mathrm{s}}^{\max }, \mathrm{MW} / \mathrm{m}^{2}$ & 1.17 & 0.63 & 0.74 & 0.83 & 1.31 & 1.13 & 1.0 & 0.63 \\
\hline Bulk power peaking factor $\mathrm{k}_{\mathrm{v}}{ }^{\mathrm{q}}$ & 1.75 & 1.9 & 1.9 & 1.9 & 1.9 & 1.9 & 1.9 & 1.9 \\
\hline Characteristic ratio $\xi, \mathrm{MW} \times \mathrm{cm}^{3} /\left(\mathrm{m}^{2} \times \mathrm{g}\right)$ & 1.3 & 0.79 & 0.79 & 0.79 & 1.3 & 1.06 & 1.06 & 0.96 \\
\hline Flattening factor $\mathrm{m}$ & 1.0 & 1.05 & 1.05 & 1.05 & 1.05 & 1.05 & 1.05 & 1.05 \\
\hline Estimated core energy content $\mathrm{W}_{\mathrm{p}, 0}, \mathrm{TW} \times \mathrm{h}$ & 2.1 & 4.5 & 5.5 & 6.4 & 6.0 & 6.0 & 6.0 & 3.7 \\
\hline Total core fuel heat-exchange surface $\mathrm{F}_{\mathrm{fe}}^{\mathrm{e}}, \mathrm{m}^{2}$ & 224 & 527 & 450 & 400 & 457 & 527 & 600 & 527 \\
\hline Circumscribed core diameter $\mathrm{D}_{\text {core }}, \mathrm{m}$ & 1.19 & 1.56 & 1.56 & 1.56 & 1.56 & 1.56 & 1.62 & 1.56 \\
\hline Core height $\mathrm{H}_{\text {core }}, \mathrm{m}$ & 1.2 & 1.64 & 1.64 & 1.64 & 1.64 & 1.64 & 1.7 & 1.64 \\
\hline Fuel U-235 enrichment $z_{5}$ & 0.141 & 0.141 & 0.141 & 0.141 & 0.141 & 0.141 & 0.12 & 0.198 \\
\hline Core average specific power density $\left\langle\mathrm{q}_{\mathrm{v}}^{\text {core }}\right\rangle, \mathrm{MW} / \mathrm{m}^{3}$ & 112.4 & 57.3 & 57.3 & 57.3 & 100.7 & 100.7 & 90.1 & 57.3 \\
\hline Initial U-235 load $\mathrm{G}_{5}^{0}, \mathrm{~kg}$ & 167 & 498 & 498 & 498 & 500 & 495 & 479 & 291 \\
\hline Number of fuel elements in core $\mathrm{n}_{\mathrm{fe}}$ & 8750 & 14970 & 10971 & 8778 & 12339 & 15164 & 16620 & 14970 \\
\hline Specific $\mathrm{U}-235$ consumption $\left\langle\mathrm{k}^{*}\right\rangle, \mathrm{g} / \mathrm{MW} \times$ day & 1.9 & 2.6 & 2.17 & 1.87 & 2.0 & 1.98 & 1.9 & 1.9 \\
\hline Max. specific accumulation of fission products $g_{f \mathrm{n}}{ }^{\max }, \mathrm{g} / \mathrm{cm}^{3}$ & 0.9 & 0.8 & 0.94 & 1.05 & 1.0 & 1.07 & 0.94 & 0.65 \\
\hline
\end{tabular}

ments in the fuel composition $b_{\mathrm{fr}}=0.59-0.678$. Options 1 through 7 use fuel elements of uranium dioxide, and option 8 uses fuel elements of intermetallic uranium. The estimation results are given in Table 1 .

\section{Discussion}

Options 1 and 2 consider cores with equal integrated indicators $A$. And option 2 seeks to reduce the average specific energy generation in the fuel composition $\left\langle q_{\mathrm{v}}^{\text {fc }}\right\rangle$ and in the core $\left\langle q_{\mathrm{v}}\right.$ core $\rangle$, as well as the maximum heat flux density in the core $q_{s}$ max. Besides, there is an increase in the estimated core energy content $W_{\mathrm{p}, 0}$. The fuel element has been somewhat redesigned to address this problem. In particular, the equivalent diameter of the swelling compensator has been reduced $\left\langle d_{\text {sc }}\right\rangle$, which has led to a reduced adjustment factor taking into account the existence of the swelling compensator $k_{\mathrm{sc}}$, and an increased share of the fuel element cross-section occupied by the fuel composition $k_{\sigma}$.

The volume fraction of the fuel elements in the dispersion fuel composition $b_{\mathrm{fr}}$ has also been increased. With a roughly equal maximum specific accumulation of fission products $g_{\mathrm{fp}}{ }^{\text {max }}$, the characteristic ratio $\xi=q_{s}^{\text {max }} / g_{\mathrm{fp}}{ }^{\max }$ for the second option will decrease due to the reduced maximum core heat flux density. Reducing the maximum heat flux density will require increasing the total core fuel heat-exchange surface $F_{\text {fe }}^{\Sigma}$. This problem can be addressed through increasing the number of the fuel elements $n_{\mathrm{fe}}^{\Sigma}$ and the core height $H_{\text {core }}$. To install more fuel elements, the diameter $D_{\text {core }}$ needs to be increased while not varying the flattening factor value $m$. The initial U-235 load $G^{0}{ }_{5}$ and the fuel matrix volume $V_{\mathrm{TM}}$ loaded into the core will be also larger. With the assumed fuel U-235 enrichment, there is a certain increase in the specific consumption of $\mathrm{U}-235\left\langle k^{*}\right\rangle$ observed for the considered option.

The integrated indicators were successively increased for core options 3 and 4 . At the same time, the core rated thermal power $Q_{\mathrm{p}, 0}$, the characteristic ratio $\xi$, the circumscribed diameter $D_{\text {core }}$, and the key design concepts for the fuel elements $\left(k_{\mathrm{sc}}, k_{\sigma}, H_{\text {core }}\right)$ and the fuel $\left(b_{\mathrm{fr}}, z_{5}\right)$ remained the same. An increase of $d_{\mathrm{fe}}$ led to a reduced number of the fuel elements in the core and, therefore, to a smaller total fuel heat-exchange area $F_{\text {fe }}^{\Sigma}$. This circumstance caused a successive increase in the maximum heat flux density $q_{s}^{\max }$ with no variation of the characteristic ratio corresponding to the growth in the maximum specific accumulation of fission products $g_{\mathrm{fp}}{ }^{\max }$. It should be also noted that these two parameters are associated, to a large extent, with the core reliability and, therefore, with a potential reduction in the specified core energy content (Korolev 2009). The fuel burn-up depth (specific accumulation of fission products) grows successively under the given initial conditions, with the estimated energy contents $W_{\mathrm{p}, 0}$ increasing simultaneously for the core option under consideration. The specific power densities in the fuel composition and in the core remain roughly the same for options 3 and 4 . The specific consumption of U-235 however decreases successively.

The cores considered for options 5, 6, and 7 have an equally higher power, $Q_{\mathrm{p}, 0}=315 \mathrm{MW}$, and an estimated energy content of $W_{\mathrm{p}, 0}=6 \times 10^{6} \mathrm{MW} \times \eta$. At the same time, options 5 and 6 have the combined indicator $A$ varying in the limits of 6 to $4.9 \mathrm{~m}$, the characteristic ratio $\xi$ in the limits of 1.3 to 1.06 , and the maximum heat flux density $q_{s}^{\max }$ in the limits of 1.31 to 1.13 , while $D_{\text {core }}=1.56 \mathrm{~m}$, the U-235 enrichment $z_{5}=0.141$, and the fuel element design parameters are constant. A smaller value of the combined indicator leads to a decreased maximum heat flux density while the maximum specific accumulation of fission products somewhat increases. A further reduction in the maximum specific accumulation of fission products can be achieved through $D_{\text {core }}$ somewhat increasing in the limits of 1.56 to $1.62 \mathrm{~m}$ (option 7). This provides for $q_{s}^{\max }$ decreasing in the limits of 1.13 to 1.0 $\mathrm{MW} / \mathrm{m}^{2}$ with $g_{\mathrm{fp}}{ }^{\max }$ reduced simultaneously in the limits of 1.07 to $0.94 \mathrm{~g} / \mathrm{cm}^{3}$, that is, there is a decrease in the fuel element energy load and, potentially, an increase in the core energy content.

Intermetallic uranium is considered as the fuel composition for core option 8 with all of the core's key parameters for option 2 remaining the same. This core has a 
smaller estimated energy content of $W_{\mathrm{p}, 0}=3.7 \mathrm{TW} \cdot \mathrm{h}$ with the allowable fuel enrichment limited to $z_{5}=0.198$.

An expression was obtained in (Korolev and Loshchakov 2004, 2010, Korolev 2008) which allows estimating, at the preliminary design stage, the required ratios of the core design and thermophysical characteristics which potentially lead to the absence of wall boiling at power values close to the rated power. This also defines the minimum value of the flattening factor

$$
\begin{gathered}
m=\left\{2500 L^{2}\left(\Delta t_{\text {core }}\right)^{1,6} /\left[\left(\left(p_{\mathrm{I}}-6.5\right) / 0.18\right)^{2}-\right.\right. \\
\left.\left.0.25\left(\Delta t_{\text {core }}\right)^{2}\right]\right\}^{0.625},
\end{gathered}
$$

where $p_{\mathrm{I}}$ is the assumed operating pressure in the primary circuit; $\Delta t_{\text {core }}$ is the core temperature difference; $L=\left(q_{s}^{\mathrm{max}}\right)^{0.2} d_{\mathrm{cl}}^{\mathrm{fe}}\left[\left(k_{\mathrm{FC}}-k_{\mathrm{BA}}\right) k_{\mathrm{v}}^{q} / D_{\text {core }}\right]^{0.8},(\mathrm{~kW} / \mathrm{m})^{0.2}$ is the parameter; $k_{\mathrm{FC}}=k_{\text {cell }} k_{\sigma} /\left(1+\left\langle k_{\text {gap }}\right\rangle\right)$ is the dimensionless coefficient taking into account the core design peculiarities and the existence of a water gap between the FA shrouds (for channel-type cores); $\left\langle k_{\text {gap }}\right\rangle$ coefficient taking into account the relative fraction of the moderator in the interchannel space of the active zone; and $k_{\mathrm{BA}}=$ $1 / k^{\text {fill }}$ ie is the coefficient taking into account the installation of burnable absorber rods, the CPS absorber rods, displacers, etc. into the FA nodes with no fuel elements.

The parameter $L$ has the dimension of the linear heat flux density and depends on the core design peculiarities, the maximum heat flux density, and the bulk power peaking factor in the core. The parameter value increases with the growth in the maximum heat flux density, the fuel cladding diameter, and the power peaking factor, as well as with the decrease in the core diameter.

\section{References}

- Knyazevsky KYu, Fadeyev YuP, Pakhomov AN, Polunichev VI, Veshnyakov KB, Kabin SV (2014) Design solutions for the RITM-200 reactor plant designed to ensure ecologically safe and cost-effective operation of a multipurpose nuclear icebreaker on the Arctic sea routes. Arktika: ekologiya i ekonomika 3(15) 87-93. [in Russian]

- Korolev VI (2008) Suppressing the wall boiling mode on the surface of fuel elements in small pressurized water reactors through the selection of the core design and thermophysical characteristics. Operation of Sea Transport: Proc. of the Makarov State Maritime Academy 2: 53-59. [in Russian]

- Korolev VI (2009) A generalizing operating and design parameter for water-cooled water-moderated reactors. Izvestiya vysshykh uchebnykh zavedeniy. Yadernaya energetika 3: 106-111. [in Russian]

- Korolev VI, Lastovtsev AYu (2008) Predicting the design characteristics of small nuclear reactor cores for surface floating facilities. Operation of Sea Transport: Proc. of the Makarov State Maritime Academy 2: 47-53. [in Russian]

- Korolev VI, Lastovtsev AYu (2010) Design of small reactor cores with the condition of preventing surface boiling on the fuel rod clad-

\section{Conclusion}

Currently, channel-type cores have begun to be installed at nuclear powered floating facilities (the floating nuclear power unit, the Arktika multipurpose nuclear icebreaker). A series of nuclear icebreakers with channel-type cores from evolution stage 2 (Sibir, Ural, Yakutiya, Chukotka, Lider) are expected to be completed in future.

The best possible selection of the reactor core design and performance characteristics and the core perfection process will require studying a large number of options meeting the given conditions. The developed procedure for rapid modeling of reactor cores allows considering the required number of options with as small costs as possible. The accuracy of calculation using the proposed procedure makes it possible to estimate fairly correctly the key design and performance parameters of the core while excluding low-efficiency options for achieving the objective set. To this end, detailed calculations need to be undertaken in future with respect to the selected options using the available designer codes. The design approaches used for the RITM-200 reactor facility aim at a potential further improvement of reactor cores and permit increasing the volume (through the height increase), the enrichment (from 7 to $19.7 \%$ ), the energy content (from 4.5 to $7.0 \mathrm{TW} \cdot \mathrm{h}$ ), and the service life (to $53000 \mathrm{~h}$ ) (Knyazevsky et al. 2014).

This rapid modeling procedure can be also used for the preliminary design of water-cooled water-moderated reactor cores for small nuclear power plants.

ding. Operation of Sea Transport: Proc. of the Makarov State Maritime Academy 4: 67-71. [in Russian]

- Korolev VI, Lastovtsev AYu (2010a) Evaluation of performance and design characteristics in design of small water-cooled water-moderated reactor cores for nuclear powered floating facilities. Operation of Sea Transport: Proc. of the Makarov State Maritime Academy 1(59): 56-62. [in Russian]

- Korolev VI, Lastovtsev AYu (2017) Ensuring the Reliability of Nuclear Reactors for Floating Facilities in Design and Operation. St. Petersburg. Makarov GUMRF Publ., 204 pp. [in Russian]

- Korolev VI, Loshchakov II (2004) A study into the surface boiling mode in transport reactor cores. Izvestiya vysshykh uchebnykh zavedeniy. Yadernaya energetika 3: 100-107. [in Russian]

- Kuznetsov VA (1988) Ship Nuclear Reactors. Leningrad. Sudostroyeniye Publ., 264 pp. [in Russian]

- Polunichev VI, Golubeva DA (2009) Selected Ways for Increasing the Corrosion Resistance of Zirconium-Alloy Components of Reactor Cores for Ships and Floating Nuclear Power Plants. Proc. of the Interbranch Workshop "Fifty Years of the Russian Nuclear Icebreaker Fleet. Building and Operation Experience and Development Prospects". Nizhny Novgorod. OKBM Afrikantov Publ., 196 pp. [in Russian] 